\title{
Estudo da conformabilidade do aço inoxidável AISI 409 sob rotas complexas de deformação
}

\author{
Frederick Louis Dias de Morais ${ }^{1}$ \\ Elaine Carballo Siqueira Corrêa ${ }^{1}$ \\ Wellington Lopes ${ }^{1}$ (1)
}

\section{Resumo}

Nas diversas operações de conformação é necessária a combinação de diferentes esforços mecânicos até que sejam alcançadas a forma e as dimensões de um produto. A severidade dessas mudanças no modo de deformação pode ocasionar modificações inesperadas no comportamento mecânico de um material, restringindo o uso do mesmo em processos industriais. Considerando essa abordagem, este trabalho apresenta o estudo da conformabilidade do aço inoxidável ferrítico AISI 409 sob duas rotas de processamento mecânico, com o objetivo de analisar a evolução da resistência mecânica e da ductilidade desse aço. Neste caso, chapas do aço AISI 409 foram submetidas a uma combinação de tensões compressivacisalhante (laminação), tração e cisalhamento (de modo direto e reverso) de forma a promover mudanças severas no modo de deformação plástica. Os resultados revelaram a influência da quantidade de pré-deformação efetiva (variando de 3,88\% a 16,50\%), do estado inicial do material (recozido e laminado a frio), do modo de deformação plástica (laminação, tração e cisalhamento) no endurecimento e na ductilidade do aço AISI 409, exibindo ainda transientes na taxa de encruamento associados com o modo de pré-deformação em laminação a frio.

Palavras-chave: Aço AISI 409; Cisalhamento; Trajetória de deformação.

\section{Study of AISI 409 stainless steel formability under complex deformation routes}

\begin{abstract}
In sheet metal forming operations is necessary a combination of several types of mechanical efforts until the final shape and dimensions of a product. The severity of these changes in the deformation mode can cause unexpected responses in the mechanical behaviour of a material, constrain its use in industrial processes. Considering this approach, this work presents a study of the formability of ferritic stainless steel (AISI 409) under two different routes of mechanical processing, with the aim of analysing the evolution of the mechanical strength and ductility of this steel. In this case, AISI 409 steel sheets were subjected to a combination of compressive shear stresses (rolling), tensile and shear (direct and reverse modes) to provide severe changes in the plastic deformation mode. The results revealed the influence of the amount of effective prestrain values (ranging from $3.88 \%$ up to $16.50 \%$ ), the initial condition of the material (annealed and cold rolled), the mode of plastic deformation (rolling, tensile and shear) on hardening and ductility of AISI 409 steel, still displaying transients of the hardening rate associated with the cold rolling prestrain mode.
\end{abstract}

Keywords: AISI 409 steel; Shearing; Strain path.

\section{Introdução}

Nas diversas operações de conformação mecânica, um material pode ser submetido a sequências diversificadas de carregamentos mecânicos, combinando, por exemplo, os esforços de tração, compressão, torção, flexão e cisalhamento para a obtenção de um produto. Essa sequência de carregamentos é denominada trajetória de deformação ou strain path e devido à essa variação nos modos de carregamento, o material poderá experimentar alterações no comportamento mecânico, como no encruamento $[1,2]$.

O encruamento está relacionado com uma diminuição na mobilidade média das discordâncias devido à multiplicação

${ }^{l}$ Engenharia de Materiais, Centro Federal de Educação Tecnológica de Minas Gerais - CEFET-MG, Belo Horizonte, MG, Brasil.

*Autor correspondente: wellingtonlopes@cefetmg.br

2176-1523 (C) 2021. Morais et al. Publicado pela ABM. Este é um artigo publicado em acesso aberto (Open Access) sob a licença Creative Commons Attribution, que permite uso, distribuição e reprodução em qualquer meio, sem restrições desde que o trabalho original seja corretamente citado. 
e à interação com outras discordâncias, com campos de tensões ou com outras barreiras à movimentação delas [3].

O encruamento é uma propriedade de extrema relevância durante a avaliação da conformabilidade de um material, sendo um método comum de promover o aumento da resistência mecânica de aços inoxidáveis ferríticos, tais como o aço AISI 409, uma vez que estes aços não são sensíveis ao endurecimento por meio de tratamentos térmicos [3].

No entanto, em uma situação real de processamento de materiais metálicos nem sempre será observada uma relação monotônica ou encruamento progressivo [4,5] entre a resistência mecânica e a deformação plástica, devido à existência de carregamentos mecânicos complexos, os quais combinam diferentes modos de deformação plástica, alterando, por exemplo, o encruamento de um material metálico.

$\mathrm{O}$ encruamento atípico de um material metálico submetido a alterações na trajetória de deformação tem sido constantemente analisado por diversos autores [1,3,6-8] e algumas características comuns têm sido observadas: a presença de transientes na tensão de fluxo e na taxa de encruamento, amaciamento e endurecimento de amostras pré-deformadas, além da variação na ductilidade, dentre outros aspectos.

Entretanto, um empecilho é criar métodos experimentais capazes de representar as condições existentes em processos reais de conformação, sem ocasionar danos aos materiais ou impor limites como a restrição à deformação plástica [9].

Considerando essa abordagem, o uso do ensaio de cisalhamento tem se mostrado eficaz para realização de ensaios do tipo Bauschinger, devido à facilidade de produção dos corpos de prova, ausência de uma zona de instabilidade plástica e a possibilidade de conduzir ensaios até um valor elevado de deformação [1].

\section{Material e métodos}

\subsection{Material}

Para a realização deste trabalho foram utilizadas chapas do aço inoxidável AISI 409 com espessura de 1,0 mm e composição química dos principais elementos químicos (\% em peso) de: $11,2 \% \mathrm{Cr}, 0,15 \% \mathrm{Mn}, 0,67 \% \mathrm{Si}, 0,14 \% \mathrm{Ni}$ e $0,021 \% \mathrm{C}$.

\subsection{Rotas de deformação}

\subsubsection{Rota 1}

Na rota 1 o aço AISI 409 foi pré-deformado em tração de dois valores de deformação efetiva $\left(\varepsilon_{\text {et }}\right)$ de $6,14 \%$ e de $11,93 \%$, o que corresponde a $25 \%$ e $50 \%$ do respectivo valor do alongamento uniforme do aço AISI 409 no estado recozido.

Neste caso, a tensão $\left(\mathrm{s}_{\mathrm{et}}\right)$ e a deformação efetiva em tração corresponderam aos respectivos valores de tensão e deformação verdadeira calculadas com uso dos valores de tensão (s) e deformação (e) convencional nas Equações 1 e 2. Em seguida foi feita a retirada dos corpos de prova de cisalhamento mediante corte e, então, deformados monotonicamente em cisalhamento na mesma direção do ensaio anterior (tração), ou seja, na direção de laminação, $0^{\circ} \mathrm{DL}$.

$$
\begin{aligned}
& s_{e t}=s \cdot(1+e) \\
& \varepsilon_{e t}=\ln (1+e)
\end{aligned}
$$

Para execução dessa rota de processamento os corpos de prova de tração foram confeccionados mediante corte com jatos d'água com dimensões especificadas pela norma ABNT NBR ISO 6892 [10] e realizados em uma máquina de ensaios universais Instron 5982 com sistema de aquisição de dados Blue Hill 3 de modo que a taxa de deformação foi igual a $1 \cdot 10^{-3} \mathrm{~s}^{-1}$ e com velocidade de $4,5 \mathrm{~mm} / \mathrm{min}$.

Os corpos de prova de cisalhamento, com comprimento de $50 \mathrm{~mm}$ e largura de $15 \mathrm{~mm}$ foram obtidos a partir do corte na região do comprimento útil dos corpos de prova de tração pré-deformados com uso de guilhotina.

O estado inicial do aço AISI 409 para a Rota 1 foi o recozido, sendo tal tratamento térmico realizado com uso de um forno mufla Analógica modelo AN1222 mediante aquecimento a $850^{\circ} \mathrm{C}$ com tempo de encharque de 30 minutos com posterior resfriamento no interior do próprio forno [5].

A tensão $\left(\mathrm{s}_{\mathrm{ec}}\right)$ e a deformação efetiva em cisalhamento $\left(\varepsilon_{\mathrm{ec}}\right)$ foram calculadas de acordo com as Equações 3 e 4, respectivamente, a partir do cálculo da tensão $(\tau)$ e da deformação $(\delta)$ cisalhantes, sendo todos estas grandezas calculadas conforme o trabalho de Rauch [11]. Este ensaio foi realizado sob velocidade constante de $0,552 \mathrm{~mm} / \mathrm{min}$, para obtenção da taxa de deformação de $1 \cdot 10^{-3} \mathrm{~s}^{-1}$.

Todos os ensaios de cisalhamento e de tração utilizados para a execução das rotas 1 e 2 foram realizados com uso de 5 amostras para cada uma das condições pesquisadas, exibindo todos estes ensaios repetibilidade adequada, conforme indicado pela descrição dos valores de desvio padrão das propriedades analisadas.

$$
\begin{aligned}
& s_{e c}=\tau \cdot 1,84 \\
& \varepsilon_{e c}=\delta / 1,84
\end{aligned}
$$

\subsubsection{Rota 2}

Na rota 2 foram utilizados dois estados iniciais do aço AISI 409: recozido e recozido/laminado a frio. Na primeira condição, o aço recozido foi submetido a dois valores de pré-deformação efetiva, $\varepsilon_{\mathrm{e}}$, em cisalhamento direto de $8,15 \%$ e de $13,40 \%$, sendo posteriormente cisalhado de forma reversa, também de dois valores de deformação efetiva, de $8,51 \%$ e de $25,10 \%$ respectivamente, culminando com o 
último ensaio de cisalhamento direto. Deve-se destacar que todos os ensaios conduzidos a $0^{\circ} \mathrm{DL}$, ou seja, na direção de laminação original da chapa.

No segundo estado inicial, o aço AISI 409 recozido foi laminado a frio com uso de um laminador Fröhling, com cilindros com diâmetro de $250 \mathrm{~mm}$ de modo a gerar uma deformação efetiva em laminação, $\left(\varepsilon_{\mathrm{el}}\right)$, de $16,50 \%$, conforme critério de von Mises, Equação 5, com uso dos valores de espessura inicial $\left(\mathrm{t}_{0}\right)$ e final $\left(\mathrm{t}_{\mathrm{f}}\right)$, considerando um estado de deformação plana.

$$
\varepsilon_{e l}=1,15 \cdot \ln \left[\left(t_{o}\right) /\left(t_{f}\right)\right]
$$

A utilização de dois estados iniciais (recozido e laminado a frio de $16,50 \%$ ) foi feita com o objetivo de investigar o efeito da condição prévia de endurecimento pelo fenômeno de encruamento existente no estado laminado a frio na resposta mecânica apresentada pelo aço AISI 409 quando deformado em cisalhamento.

Para os dois estados iniciais desta rota de deformação foram adotados dois valores de pré-deformação em cisalhamento direto, de $3,88 \%$ e de $7,58 \%$, com posterior cisalhamento reverso, sendo este também conduzido com uso de dois valores de deformação efetiva: de 6,99\% e de $11,09 \%$, respectivamente. Por fim, foi feito o segundo cisalhamento direto sendo este o último modo de deformação plástica aplicado ao aço AISI 409.

Destaca-se que para a realização do carregamento do tipo Bauschinger a partir da combinação dos cisalhamentos direto e reverso foi necessário promover um giro dos respectivos corpos de prova de $180^{\circ}$.

\section{Resultados e discussões}

\subsection{Comportamento mecânico do aço AISI 409 rota 1}

Na Figura 1a são mostradas as curvas de tensão-deformação efetiva referentes à rota 1 para o aço AISI 409 para os dois

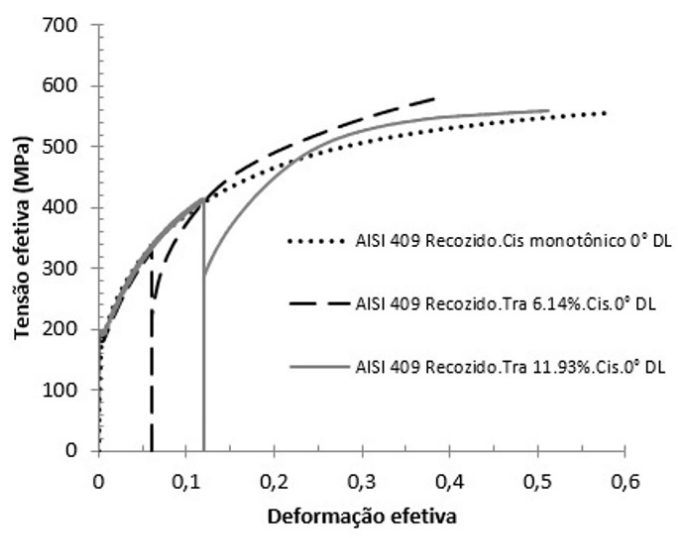

(a) valores de pré-deformação em tração. Verifica-se pela análise dessas curvas que o material apresentou no recarregamento em cisalhamento um valor de tensão de fluxo (tensão na parte plástica), para o mesmo valor de deformação efetiva, menor que o detectado na condição de deformação monotônica (condição essa realizada sem mudança do modo de deformação plástica, apenas o cisalhamento).

O aço AISI 409 apresentou comportamento mecânico classificado como sendo do tipo 1, conforme definido por Chung e Wagoner [12], ou seja, tensão de fluxo no reinício do recarregamento em cisalhamento inferior ao último valor da tensão de fluxo ao término da pré-deformação em tração, acompanhado por um aumento da taxa de encruamento.

Esse amaciamento, indicado pela queda da tensão de fluxo no recarregamento em cisalhamento foi observado por Lopes et al. [13] em uma rota de carregamento do tipo laminação/cisalhamento em amostras de aço de baixo teor de carbono e do alumínio A1050, sendo tal comportamento associado com a evolução estrutural e com a orientação cristalográfica assumida por esses materiais.

Wang et al. [9] perceberam que esse amaciamento pode ser associado ainda com a formação de microbandas de cisalhamento que se tornam ativas durante o recarregamento $\mathrm{e}$ assim, atravessam as paredes da subestrutura de discordâncias geradas na pré-deformação.

Com a continuidade da deformação plástica em cisalhamento nota-se a recuperação da resistência mecânica do aço AISI 409, sendo isso indicado pela inclinação das curvas de tensão-deformação efetiva que se posicionaram acima da curva do carregamento monotônico em cisalhamento. Tal resposta pode ser atribuída ao estabelecimento de uma subestrutura de discordâncias que seja típica do último modo de solicitação mecânica, ou seja, o cisalhamento, que contribui para o endurecimento do material, situação essa em que é comum a presença de uma subestrutura de discordância com paredes de elevada densidade de discordâncias (Dense Dislocations Walls - DDW's, do termo em inglês $[7,9]$.

Verifica-se ainda que tal recuperação da resistência mecânica foi maior para o menor valor de pré-deformação em

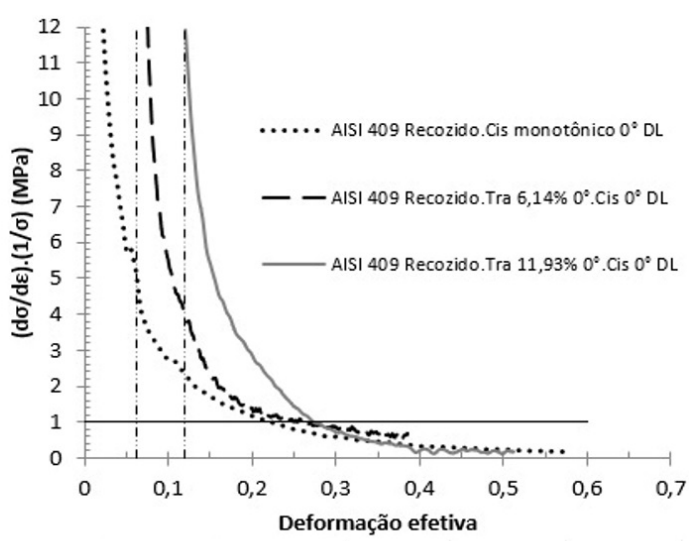

(b)

Figura 1. Curvas tensão-deformação efetiva (a) e curvas taxa de encruamento normalizada-deformação efetiva do aço AISI 409 referentes à rota $1(b)$. 
tração, 6,14\%, sugerindo que a reorganização da subestrutura de discordâncias devido à mudança do modo de deformação plástica (tração para cisalhamento) foi facilitada para a menor quantidade de pré-deformação [11].

Na Figura 1b nota-se a ausência de indícios de transientes na taxa de encruamento (oscilação entre um estágio de queda com posterior aumento da taxa de encruamento) para as duas condições de pré-deformação em tração da rota 1 .

Verifica-se ainda que o início da instabilidade plástica, indicada quando o valor da taxa de encruamento normalizada (de/ds.1/s) alcança um valor menor que a unidade (1) foi maior para o maior valor de pré-deformação em tração, conforme indicado na Tabela 1 [14], a qual exibe o valor do coeficiente para o último modo de deformação (cisalhamento).

Tal comportamento confirma que o aumento da quantidade de deformação plástica no último modo de deformação (cisalhamento) tende a promover o endurecimento à medida que se estabelece uma subestrutura de discordâncias específica, reforçando assim, o endurecimento por encruamento do aço AISI 409 [9].

\subsection{Comportamento mecânico do Aço AISI 409 rota 2}

\subsubsection{Rota do tipo Bauschinger para o aço AISI 409 recozido}

Na Figura 2 é possível observar o comportamento mecânico do aço AISI 409 recozido na rota 2, além da curva referente ao carregamento monotônico, com uso de setas para indicação de cisalhamento direto e reverso. Em relação ao comportamento do material pré-deformado de $8,15 \%$ (linha tracejada), nota-se uma característica do efeito Bauschinger: a queda da tensão de fluxo durante o cisalhamento reverso. Percebe-se ainda que com o aumento da quantidade de deformação em cisalhamento direto a respectiva curva tensão-deformação efetiva do aço consegue

Tabela 1. Coeficientes de encruamento, $\mathrm{n}$, do aço AISI 409 para a rota 1

\begin{tabular}{cc}
\hline Sequência de carregamento & Coeficiente de encruamento, $\mathbf{n}$ \\
\hline Monotônico $0^{\circ} \mathrm{DL}$ & $0,22 \pm 0,010$ \\
Tração $6,14 \%+$ cis. $0^{\circ} \mathrm{DL}$ & $0,26 \pm 0,006$ \\
Tração $11,93 \%+$ cis. $0^{\circ} \mathrm{DL}$ & $0,27 \pm 0,008$ \\
\hline
\end{tabular}

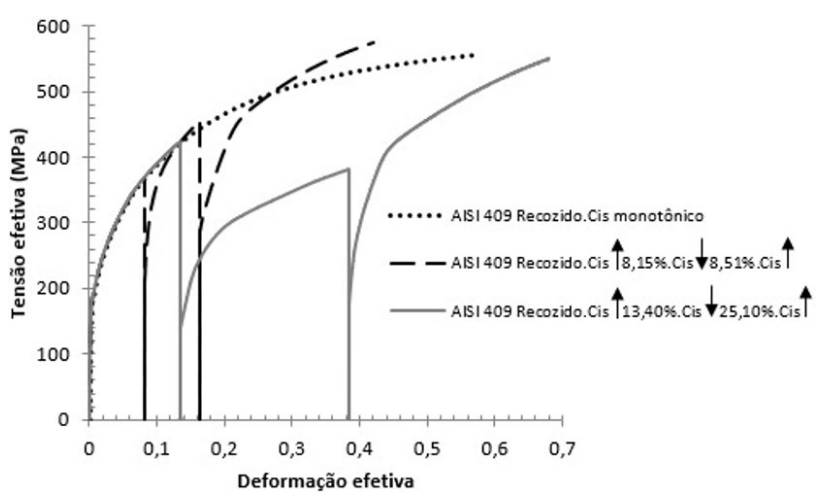

Figura 2. Curvas tensão-deformação efetiva do aço AISI 409 recozido, rota 2 . ultrapassar a curva do carregamento monotônico, sugerindo assim, uma recuperação da capacidade de endurecimento por deformação plástica.

Tal comportamento das curvas tensão-deformação efetiva aponta uma modificação da subestrutura de discordâncias e da orientação cristalográfica do aço AISI 409.

Neste caso, Han et al. [15] observaram uma condição de aumento da taxa de encruamento após o recarregamento a partir da reorientação das componentes de tensão interna oriundas da pré-deformação para três tipos diferentes de aços (aço de baixo teor de carbono, um aço HSLA e um aço DP) similar ao aço AISI 409.

Por outro lado, na condição de pré-deformação de 13,40\% o aço AISI 409 apresentou um amaciamento permanente, indicado pela queda da tensão de fluxo no início do recarregamento em cisalhamento em relação ao carregamento monotônico e pelo fato de a curva tensão-deformação efetiva ter permanecido sempre abaixo da curva do carregamento monotônico. Tal amaciamento, que tende a aumentar com o acréscimo da pré-deformação, pode ser associado ao desenvolvimento de tensões reversas (back stress, do termo em inglês) que tendem a favorecer a movimentação das linhas de discordâncias durante o recarregamento em cisalhamento reverso, além da possível ocorrência da aniquilação/dissolução das linhas de discordâncias entre os carregamentos concorrentes (cisalhamento direto e reverso), reduzindo assim, o encruamento do material, mas que permite a recuperação com o posterior aumento da quantidade de deformação em cisalhamento reverso [16].

Em relação à evolução da taxa de encruamento normalizada do aço AISI 409 recozido e pré-deformado em cisalhamento direto de $8,15 \%$ e de $13,40 \%$ na rota 2 (Figura 3 a e Figura 3b), é possível notar um comportamento estável da mesma, sem a presença de transientes, para os dois valores de pré-deformação. Nota-se ainda que a instabilidade plástica do material foi adiada em relação ao carregamento monotônico a partir da análise dos valores do expoente de encruamento identificados durante o segundo cisalhamento direto, Tabela 2. Deste forma, pode-se afirmar que o encruamento do aço AISI 409 foi modificado de modo mais intenso sob a rota de carregamento do tipo Bauschinger do que na rota de carregamento ortogonal (tração/cisalhamento, vide Tabela 1), sendo tal efeito foi mais destacado para o maior valor de pré-deformação em cisalhamento.

Deste modo, percebe-se que, apesar da ocorrência do amaciamento nos estágios iniciais de deformação sob cisalhamento reverso, esse aço conseguiu recuperar sua capacidade de endurecimento por deformação plástica com a continuidade da deformação em cisalhamento.

\subsubsection{Rota do tipo Bauschinger para o aço AISI 409 recozido/laminado}

Na Figura 4 é observado o comportamento mecânico do aço AISI 409 na condição recozido/laminado a partir das respectivas curvas de tensão-deformação efetiva. Similarmente ao detectado no estado apenas recozido desse aço nota-se novamente as características comum a um carregamento do tipo Bauschinger, ou seja, a queda da tensão de fluxo no recarregamento, além do amaciamento permanente do 
Tabela 2. Coeficientes de encruamento, $n$, do aço AISI 409 recozido para a rota 2

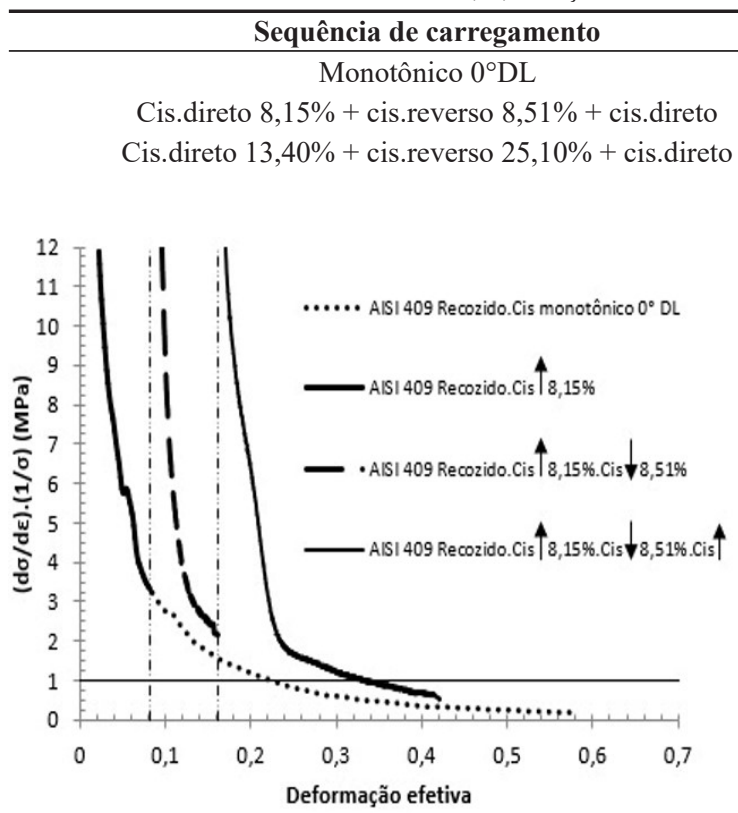

(a)

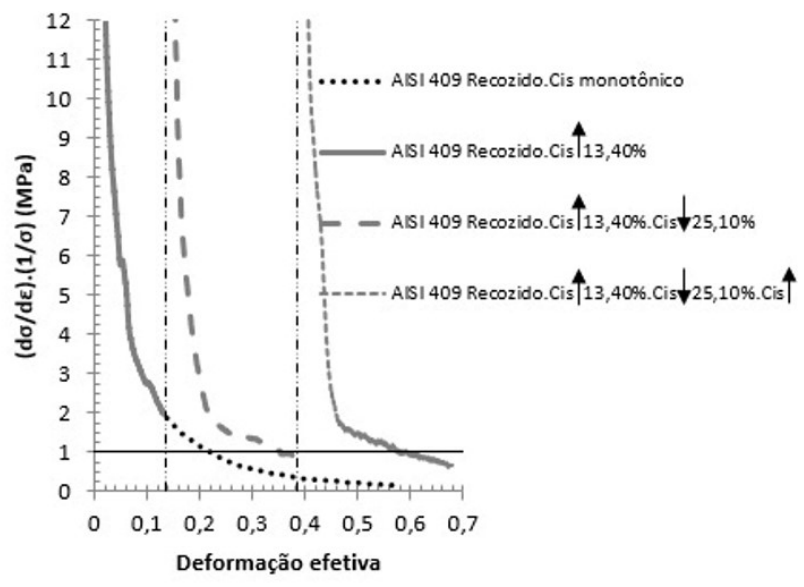

(b)

Figura 3. Curvas taxa de encruamento normalizada-deformação efetiva para a rota 2 do aço AISI 409 recozido/cisalhado direto/cisalhado reverso/cisalhado direto com pré-deformação de: (a) $8,15 \%$ e (b) $13,40 \%$.

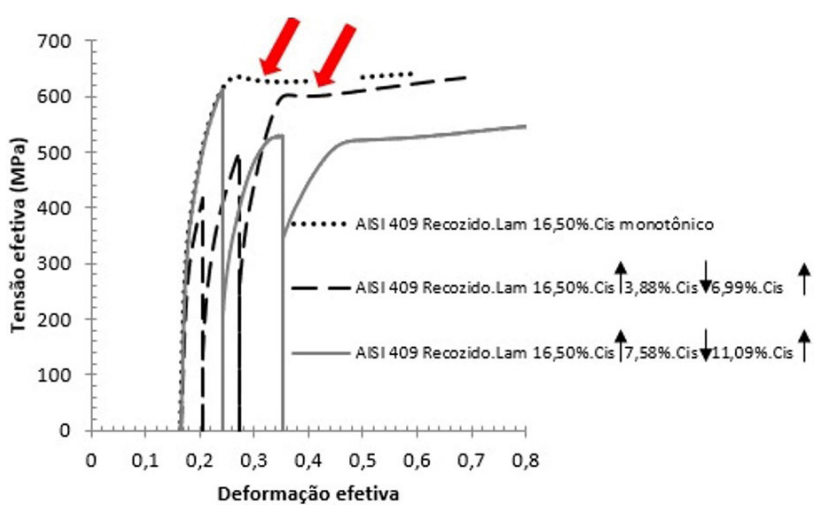

Figura 4. Curvas tensão-deformação efetiva do aço AISI 409 recozido/ laminado, referentes à rota 2 e ao carregamento monotônico em cisalhamento.

material em relação ao observado pela curva do carregamento monotônico.

Em relação à resposta apresentada pelo aço AISI 409 pré-deformado de 3,88\% (linha tracejada), observa-se um aumento da resistência mecânica do material ao longo das etapas do processamento. Entretanto, o endurecimento por deformação plástica (encruamento) não foi suficiente para ultrapassar a curva de tensão-deformação efetiva do carregamento monotônico, como observado no caso do aço AISI 409 apenas recozido (Figura 2). Essa mudança revela o efeito do estado inicial desse material no subsequente comportamento mecânico com o acréscimo da quantidade de deformação plástica em cisalhamento.

Verifica-se que o aumento da quantidade de pré-deformação em cisalhamento direto, após a etapa de laminação a frio, intensificou o amaciamento sofrido pelo aço AISI 409 durante o recarregamento em cisalhamento reverso e direto, indicando que o desarranjo subestrutural com a mudança do modo de deformação depende do estado inicial, do modo de deformação plástica assim como da quantidade de pré-deformação [15].

Observa-se ainda que para os dois valores de pré-deformação em cisalhamento direto, que a curva referente ao segundo cisalhamento direto exibiu uma queda (amaciamento) com posterior elevação (endurecimento), sinalizado a presença de transientes na taxa de encruamento normalizada e, consequentemente, uma maior desestruturação da subestrutura de discordâncias [17].

Por fim, verifica-se a presença de uma pequena estagnação da tensão de fluxo durante o segundo cisalhamento direto (indicada pela presença de setas na Figura 4) a qual pode ser correlacionada com uma dificuldade maior quanto ao estabelecimento de uma nova subestrutura para essa condição de deformação plástica, em detrimento à dissolução de uma subestrutura pré-existente construída durante as etapas de deformação prévia (laminação, cisalhamentos direto e reverso) [12].

Em relação à evolução da taxa de encruamento normalizada do aço AISI 409 recozido/laminado, Figura 5, é possível observar, a presença de transientes na taxa de encruamento para os dois valores de pré-deformação em cisalhamento direto. Esse resultado, comparado com os dados exibidos na Figura 3, indica o efeito do modo e da quantidade de pré-deformação em laminação a frio na reestruturação da subestrutura de linhas de discordâncias, a qual pode ser relacionada com a presença desses transientes, associada ainda à provável modificação da orientação cristalográfica ao mudar o modo de deformação plástica (laminação para cisalhamento) [17]. 


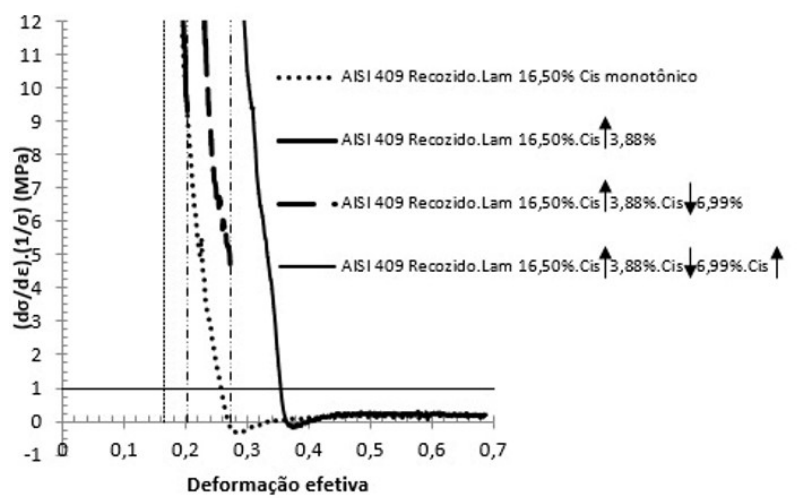

(a)

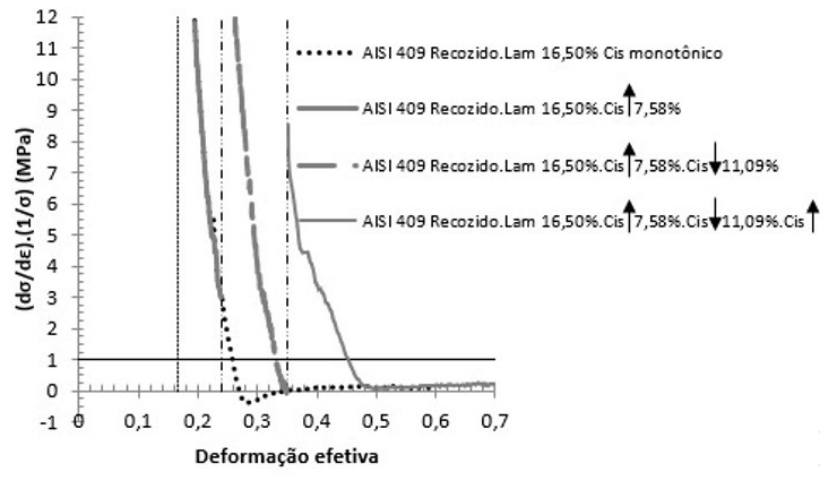

(b)

Figura 5. Curvas taxa de encruamento normalizada-deformação efetiva para a rota 2 do aço AISI 409 recozido/laminado/cisalhado direto/ cisalhado reverso/cisalhado direto com pré-deformação em laminação de 16,50\% e em cisalhamento direto de: (a) 3,88\% e (b) 7,58\%.

Tabela 3. Coeficientes de encruamento, $n$, do aço AISI 409 recozido/laminado para a rota 2

\begin{tabular}{cc}
\hline Sequência de carregamento & Coeficiente de encruamento, $\mathbf{n}$ \\
\hline Lam. $16,50 \%+$ cis. $0^{\circ} \mathrm{DL}$ & $0,26 \pm 0,013$ \\
Lam. $16,50 \%+$ cis.direto $3,88 \%+$ cis.reverso $6,99 \%+$ cis.direto & $0,35 \pm 0,011$ \\
Lam. $16,50 \%+$ cis.direto $7,58 \%+$ cis.reverso $11,09 \%+$ cis.direto & $0,45 \pm 0,009$ \\
\hline
\end{tabular}

Ainda referente à análise da Figura 5, nota-se um cruzamento entre as curvas da taxa de encruamento normalizada do aço AISI 409 pré-deformado de $3,88 \%$ e do carregamento monotônico, Figura 5a. Esse cruzamento sugere que com a continuidade da deformação plástica durante o segundo cisalhamento direto, há uma tendência ao estabelecimento de uma orientação cristalográfica preferencial e um arranjo subestrutural que sejam típicos do carregamento monotônico em cisalhamento do aço AISI 409 [11].

Em relação à evolução da taxa de encruamento do aço AISI 409 recozido/laminado e pré-deformado de 7,58\%, Figura $5 \mathrm{~b}$, nota-se que o transiente na taxa de encruamento normalizada foi menor que o percebido para o menor valor de pré-deformação em cisalhamento direto, ou seja, de 3,88\%.

Com isso, pode-se compreender que a menor oscilação da taxa de encruamento normalizada para o aço AISI 409 pré-deformado de 7,58\% esteja associada com a presença de uma subestrutura de discordâncias e textura mais estáveis devido, exatamente, a essa maior quantidade de deformação plástica [1].

Os valores do expoente de encruamento, $\mathrm{n}$, identificados durante o último modo de deformação plástico mostrados na Tabela 3 revelam o acréscimo desse parâmetro com o aumento da quantidade de pré-deformação em cisalhamento direto para o aço AISI 409 recozido/laminado, assim como detectado para a condição de carregamento do tipo Bauschinger em amostras não pré-deformadas em laminação (vide dados da Tabela 2), sugerindo que o modo de deformação plástica, a sequência de aplicação dos mesmos e, principalmente, a quantidade de deformação plástica para cada uma dessas etapas de deformação são as variáveis que mais afetam o comportamento mecânico do aço AISI 409 quando exposto a uma mudança na trajetória de deformação.

\section{Conclusões}

As rotas de carregamento aplicadas ao aço AISI 409 indicaram:

a) a eficiência da técnica de cisalhamento para a realização ensaios do tipo Bauschinger, além de promover mudanças sucessivas na trajetória de deformação;

b) o efeito da quantidade de pré-deformação, do estado inicial, do modo de deformação plástica e da sequência de aplicação dos esforços mecânicos nas respostas apresentadas pelo aço AISI 409, como a queda da resistência mecânica durante o recarregamento em cisalhamento e a quantidade de deformação efetiva uniforme até o início da instabilidade plástica;

c) de modo geral, verificou-se que o amaciamento do aço AISI 409 para todas as rotas de deformação, sendo maior para a rota Bauschinger com pré-deformação em laminação, enquanto a recuperação da capacidade de endurecimento foi maior para a rota tração/cisalhamento;

d) a rota do tipo Bauschinger no estado recozido exibiu o maior valor de deformação efetiva uniforme até o início da instabilidade plástica;

e) a presença de transientes na taxa de encruamento foi relacionada com o modo de pré-deformação (laminação a frio) na rota do tipo Bauschinger.

\section{Agradecimentos}

Os autores agradecem ao CEFET-MG e CAPES pelo desenvolvimento da pesquisa. 


\section{Referências}

1 Laukonis JV, Ghosh AK. Effects of strain path changes on the formability of sheet metals. Metallurgical Transactions. 1978;9(12):1849-1856.

2 Othmen KB, Sai K, Manach PY, Elleuch K. Reverse deep drawing process: material anisotropy and work-hardening effects. Journal of Materials: Design and Applications. 2019;233(4):699-713.

3 Dieter GE. Mechanical metallurgy. 3rd ed. New York: McGraw-Hill Companies; 1986.

4 Lucchetta A, Auslender F, Bornert M, Kondo D. A double incremental variational procedure for elastoplastic composites with combined isotropic and linear kinematic hardening. International Journal of Solids and Structures. 2019;158:243-267.

5 Badreddine H, Saanouni K, Labergère C, Duval J-L. Effect of the kinematic hardening on the plastic anisotropy parameters for metallic steels. Comptes Rendus. Mécanique. 2018;346(8):678-700.

6 Meyers MA, Chawla KK. Princípios de metalurgia mecânica. São Paulo: Edgard Blücher; 1982.

7 Rauch EF, Gracio JJ, Barlat F, Lopes AB, Duarte JF. Hardening behaviour and structural evolution upon strain reversal of aluminum alloys. Scripta Materialia. 2002;46(12):881-886.

8 Qin J, Holmedal B, Hopperstad OS. Experimental characterization and modelling of aluminum alloy AA3103 for complex single and double strain-path changes. International Journal of Plasticity. 2019;112:158-171.

9 Wang H, Lu C, Tieu K. Crystal plasticity modelling of microbands in a rolled aluminium single crystal. Materialia. 2019;8:100488.

10 Associação Brasileira de Normas Técnicas. ABNT NBR 6892: materiais metálicos: ensaio de tração à temperatura ambiente. ABNT; 2018.

11 Rauch EF. The flow law of mild steel under monotonic or complex strain path. Diffusion and Defect Data, Solid State Data. Part B, Solid State Phenomena. 1992;23-24:317-333.

12 Chung K, Wagoner RH. Effect of stress-strain-law transients on formability. Metallurgical Transactions. 1986;17(6):1001-1009.

13 Lopes AB, Rauch EF, Gracio JJ. Textural vs structural plastic instabilities in sheet metal forming. Acta Materialia. 1999;47(3):859-866.

14 Zandrahimi M, Platias S, Frice D, Barrett D, Bate PS, Roberts WT. Effects of changes in strain path on work hardening in cubic metals. Metallurgical Transactions. 1989;20(11):2471-2482.

15 Han K, Van Tyne CJ, Levy BS. Effect of strain and strain rate on the Bauschinger effect response of three different steels. Metallurgical and Materials Transactions. 2005;36(9):2379-2384.

16 Mahato JK, De PS, Sarkar A, Kundu A, Chakraborti PC. Effect of prestrain and stress rate on Bauschinger effect of monotonically and cyclically deformed OFHC copper. Procedia Engineering. 2014;74:368-375.

17 Pham CH, Adzima F, Coer J, Manach PY. Anti-buckling device for ultra-thin metallic sheets under large and reversed shear strain paths. Experimental Mechanics. 2017;57(4):593-602.

Recebido em: 7 Abr. 2020

Aceito em: 30 Out. 2020 